УДК 338(09)

ББК 65.03

DOI 10.17150/2308-2588.2017.18(3).547-570

Ю. В. Латов

Институт соииологии РАН, Финансовый университет при Правительстве РФ, 2. МоскВа, Российская Федерация

Н. О. Воскресенская Финансовый университет при Правительстве РФ, г. Москва, Российская Федерациия

\title{
"पЁРТОВА ДЮНИНА॥ ПОМОЩНИКОВ ПРЕПОДАВАТЕЛЮ: основные типЫ творческих учебных заданий при преподавании экономической истории
}

Аннотация. Авторы данной методической публикации на основе опыта преподавания в Финансовом университете выделяют 13 различных типов заданий, которые рекомендуется применять для проверки знаний студентов на семинарах и на экзаменах. На каждый тип заданий приведены конкретные примеры (некоторые из них - с ответами). Обращается внимание на необходимость при помощи тестов тренировать у студентов как механическую память (запоминание терминов, дат, имен), так и креативные способности. Данная методическая разработка является частью работы над «Практикумом по экономической истории», который готовится под руководством д.э.Н. профессора Р. М. Нуреева.

Ключевые слова. Преподавание экономической истории в вузе, учебно-методическое обеспечение. 
Financial University under the Government of the Russian Federation, Moscow, Russian Federation

N. O. Voskresenskaya

Financial University under the Government of the Russian Federation, Moscow, Russian Federation

\title{
BAKER'S DOZEN OF TEACHER'S HELPERS:

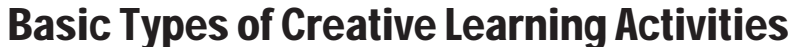

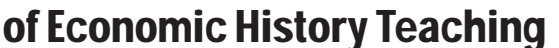

\begin{abstract}
The authors of the article highlight 13 different types of tasks that are recommended to be used for the check of students' seminar and exam tasks based on teaching practice in Financial University. Each type of the tasks has corresponding examples (some - with answers). The authors underline necessity to train both mechanical memory (memorizing of terms, dates, names) and creative abilities. This guidance paper is a part of "Case study of economic history» that is developed under the guidance of Doctor of Economic Sciences, Professor R. M. Nureev.
\end{abstract}

Keywords. Teaching of economic history in the university, methodological support.

В предыдущих публикациях в журнале «Историко-экономические исследования» об использовании заданий (тестов) в вузовских курсах по экономической истории* приводились многочисленные примеры таких заданий. Авторы данной публикации намерены дать типологию этих заданий и дать общие рекомендации по их составлению.

* Латов Ю. В. Занимательные задачи по экономической истории / Ю. В. Латов // Историко-экономические исследования. 2003. № 2-3. С. 184-196; Латов Ю. В. Творческие задания по экономической истории / Ю. В. Латов // Историко-экономические исследования. 2017. Т. 18, № 1. С. 155-189. 
Обычно при тестировании знаний студентов по экономической истории им задают короткие вопросы, на которые в принципе (если студент знает соответствующую тему) можно на основе учебника дать короткий же ответ в 2-3 фразы. Речь идет о типовых заданиях следующего вида:

Bопрос. В начале XIX в. крепостное право на территории Германии было отменено на тех же условиях, что и позже (b 1861 г.) в России. Какой специфический источник накопления капитала $b$ сельском хозяйстве сформировался в этих странах в связи с отменой крепостного права? Одинаково ли успешно его использовали землевладельцы этих стран?

Ожидаемый ответ. В Германии и в России при отмене крепостного права крестьяне получили мичную свободу, но землю должны были выкупать (В. И. Ленин называл это «прусским типом аграрного капитализма» [2, с. 150]). Соответственно, спеиифический источник накопления капитала, характерный для Германии и России XIX в. - это выкупные платежи крестьян. Однако если в Германии помещики (юнкеры) использовали эти доходы для развития агробизнеса, то русские помещики чаще использовали их в чисто потребительских целях.

Предлагаемые ниже учебные задания носят более творческий характер - они либо рассчитаны на более широкие (выходящие за рамки стандартного учебника) знания, либо требуют более развернутого ответа. Эти задания-тесты предназначены в первую очередь для студентов, проходящих в вузах России курс «Экономическая история» (или «История») обычно на первом курсе.

Авторами выделено 13 типов различных творческих заданий. Используемая типология, конечно, имеет несколько условный характер, некоторые из приведенных задач можно отнести сразу к 2-3 типам. 


\section{1-й тип: выберите правильный ответ}

Это - наиболее традиционный тип теста. При его применении можно составлять задания как более простые, так и более сложные. Чаще всего этот тип задания применяют для выявления формального (во многом механического) запоминания студентом наиболее важных событий, имен ученых и т. д.

Вот пример подобного задания:

(1) История экономики как наука сорормировалась:

a) $в$ античной Греции $b$ V b. до н. э.;

б) в средневековом Китае во I тыс. н. э.;

в) в России в XVIII b. при правлении Петра I;

2) $b$ Западной Ebpone $b$ XIX b.;

д) в США $b$ XX $b$.

В этом вопросе есть некоторая двусмысленность, которую могут заметить только специалисты по экономической истории: в зависимости от того, что считать наукой - сбор фактов или в первую очередь их концептуальное осмысление, - можно выбрать и обосновать разные варианты ответа. При разбоpe со студентами данного вопроса целесообразно обратить внимание на то, что экономическая история как аналитическая наука сформировалась, безусловно, в трудах представителей немецкой исторической школы. Однако экономическая история как систематический сбор информации о событиях именно хозяйственной жизни появилась еще в средневековом Китае (разделы «Ши хо чжи» - «Записи о продовольствии и ценностях» - в династийных летописях [4]).

Вопросы на выбор правильного ответа в принципе можно использовать и менее формально - для выявления умения студента не просто запоминать ключевые факты, но и осмыслять их. В качестве примера более творческого по содержанию задания можно привести такой пример: 
(2) Кем был Господин Великий Новгород по отномению к Ганзе?

а) конкурентом в торговле;

б) военным противником в борьбе за земли Прибалтикu;

в) торговым партнером;

г) членом самой Ганзы;

д) союзником в борьбе за свободу торговли в Балтииском море.

\section{2-й тип: установите соответствие}

Тесты такого типа в Финансовом университете в 2017 г. уже стали внедряться в экзаменационные билеты. Они удобны тем, что позволяют проверить знания студентов сразу по многим событиям, или эпохам, или концепциям.

Вот более простой и формальный пример подобного теста, уместный для использования в экзаменационном билете:

(3) Установите соответствие между учеными и их концепциями:

\begin{tabular}{|l|l|}
\hline A. Тойнби & $\begin{array}{l}\text { В развитии человечества выделяются } \\
\text { три последовательных стадии: аграрная, } \\
\text { индустриальная, постиндустриальная }\end{array}$ \\
\hline У. Ростоу & $\begin{array}{l}\text { Всемирная история есть просто сумма } \\
\text { ицвилизаиии, каждая из которых прошла } \\
\text { через присущие именно ей стадии в раз- } \\
\text { витии }\end{array}$ \\
\hline К. Маркс & $\begin{array}{l}\text { Самая длительная стадия в истории че- } \\
\text { ловечества - стадия аграрного общества }\end{array}$ \\
\hline О. Тоффлер & $\begin{array}{l}\text { В истории человечества за стадией фео- } \\
\text { дализма следует капитализм }\end{array}$ \\
\hline
\end{tabular}

В тесты данного типа можно «закладывать» и более сложное содержание, рассчитанное на студентов-эрудитов. Вот пример более творческого вопроса: 
(4) Установите соответствие между странами и теми нарицательными «кличками» (итампами), которыми их называли в XIX веке

\begin{tabular}{|l|l|}
\hline Великобритания & «Больной человек Европы» \\
\hline Турияия & «Мастерская мира» \\
\hline Франциия & «Жандарм ЕВропы» \\
\hline Россия & Государство-рантье \\
\hline
\end{tabular}

При аудиторном разборе данного теста необходимо попросить студентов не просто найти соответствия, но и объяснить происхождение этих публицистических штампов.

\section{3-й тип: установите правиЛьную последовательность событий}

Такие тесты в Финансовом университете тоже стали уже применяться в экзаменационных билетах, поскольку они позволяют выявить способность студентов запоминать «сетку» основных событий в разных странах и свободно в ней ориентироваться. Важно отметить, что для правильного ответа на вопросы данного типа даже не обязательно, чтобы студент точно помнил даты, достаточно его знаний общей последовательности событий.

Примером задания подобного типа может быть следующий вопрос:

(5) Установите последовательность событий в России XVI-XVII bb., связанных с введением крепостного права:

а) введение заповедных иет;

б) введение Юрьева дня;

в) политика опричнины;

г) введение урочных лет;

д) отмена Юрьева дня.

Наиболее интересные примеры заданий подобного типа - установление последовательности и взаи- 
мосвязи событий, происходящих в разных странах. Вот пример такого задания:

(6) Расположите события $\mathrm{b}$ хронологической последовательности (максимально - 5 баллов). Есть ии между какими-либо из этих событий причинно-следственные связи? Аргументируйте свой ответ. (Полный ответ оценивается на 15 балиов.)

a) начало книгопечатания в России;

б) Раскол в русской православной изеркви;

в) изобретение книгопечатания в Западной Европе;

г) Реформаичя;

д) впервые в мире изобретено книгопечатание.

\section{4-й тип: найдите ошибкки в тексте}

Задание такого типа является достаточно сложным и для составителя-преподавателя, и для решающего студента. Формулировка задания должна быть большой, включающей малоизвестные факты, чтобы ошибочные утверждения не слишком выделялись на общем фоне.

Вот один из более простых примеров задания такого типа:

(7) Найдите допущенную в тексте ошибку:

С середины IX b. во Франции был установлен порядок, в соответствии с которым каждый человек был обязан подчиняться власти сеньора. Те, кто не имел сеньора, были обязаны его наитти, - в противном случае они не пользовались зашитой закона, ююбому их можно было продать в рабство и даже убить. Сеньором для крестьянина мог быть фреодал, стоящий на любой ступени феодальной лестницы, и даже сам король. Крестьяне же всегда занимали самую низшую ступень в системе вассалитета. Король требовал от своих крестьян-вассалов несения военной службы.

В данном примере найти единственную ошибку относительно легко: крестьяне не входили в систему 2017. T. 18, № 3. C. 547-570 
дворянского вассалитета и, соответственно, не несли военную службу.

А вот более трудный пример подобного задания, где допущено сразу несколько ошибок.

(8) Найдите не менее 5-ти ошибок в данном тексте.

Центром внешней торговли в Западной Европе $b$ nериод классического средневековья $b$ силу сочиальных и природных условий было только Средиземное море. В северных морях торговля почти не велась: зимой моря замерзали, а в теплое время их контролировали викинги, которые не только грабили торговые корабли, но и нападали на прибрежные города. Из Западной Европы на Восток везли металические изделия, кружево, меха, рыбу, вина, рабов; $b$ Западную Европу из стран Востока ввозили шелк, меха, слоновую кость, пряности, красители и хлеб. Средиземноморскую торговлю контролировали в этот период купиы итальянских городов-государсть (Пиза, Генуя, Венеция), которые часто воевали друг с другом ради передела зон влияния. Вывоз по стоимости был в обычные годы примерно равен ввозу, хотя в годы частых неурожаев в Западной Eвропе для закупок продуктов итальянские купцы активно вывозили в плодородные восточные страны золото и серебро.

\section{5-й тип: установите страну}

Задание данного типа требует от преподавателя высокой эрудиции. Чтобы задание не было слишком легким, надо стараться избегать упоминаний в таком задании общеизвестных имен исторических деятелей и фактов. Изображаемая в задании страна должна характеризоваться «остранённо», напоминая условную страну из какого-нибудь историко-фантастического романа. Студенту придется проявить высокую эрудицию, чтобы быстро решить такое задание.

Вот относительно простой пример: 
(9) Определите страну и период:

На территории этой современной страны никогда (вплоть до XIX в.) не было государства, которое бы объединяло всю ее территорию. В описываемый период в стране было множество соперничавших и враждующих между собой княжеств. Наиболее Влиятельным было государство, которое возглавлял правитель Харша. За время войны, которую он вел, - настолько тяжелую и насыщенную военными действиями, что «со слонов не снимали сбрую, а с воинов - шлем», - он сумел овладеть северными территориями страны, южные территории оставались раздробленными. Однако после его смерти государство вновь распалось на множество политических объединений, и ни одно из них не оказалось достаточно сильным, чтобы вновь объединить страну. Раздробленность этой страны стала причиной того, что разные ее части то и дело завоевывамись внешними захватчиками.

Если у студента есть под рукой ПК (а у современных студентов компьютер-планшетка с выходом в Сеть постепенно вытесняет тетрадь для конспектов), то он по имени упомянутого в тексте правителя быстро найдет ответ: это - Индия, VII век. Поэтому лучше, с тем чтобы ответ было не так легко найти, подобные «подсказки» из текста убирать.

Вот примеры более сложных тестов данного типа:

(10) Назовите страну, о которой здесъ идет речъ.

Промышленный переворот $b$ этой стране начался $b$ 1830-1840-е ге. Он тормозился низким уровнем урбанизации и образования: $b$ городах $b$ это время проживало мишь около 6\% населения, примерно таким же был уровень грамотности. Только в 1860-е гг. система откупа налогов была заменена акцизами, а подоходное налогообложение сорормировалось лишь в начале XX в. Тем не менее, проведенная $b$ 1890-е годы успешная денежная реформа, суть которой заключалась $b$ установлении $b$ стране золотого стандарта, обеспечила этой стране место $b$ небольшой 
группе стран, обладающих самой стабильной валютой b supe.

(11) Назовите страну, о которой здесь идет речь.

Почти 80 \% территории этой страны В силу специифики природных условий практически полностью выброшены из народнохозяйственного оборота, однако жители всегда активно занимались и ремеслом, и сельским хозяйством. В период раннего средневековья рабов, занятых в сельском хозяйстве, и тех, кто выполнял функиии прислуги $b$ доме, хозяин мог по своему усмотрению продать и даже убить. Но такие нормы не распространялись на рабов-ремесленников: убивать их было запрещено. Причина была в том, что эти рабы - захваченные в плен ремесленники из соседних стран - были носителями более высокой материальной культуры, чем местные жители.

\section{6-й тип: объясните картину}

Задания данного типа можно применять, только если в семинарских аудиториях есть проектор. Преподаватель должен заранее подготовить слайд с максимально крупной и четкой репродукцией картины, посвященной каким-либо историческим событиям или явлениям, и попросить студентов, глядя на картину, либо определить, какое именно событие/явление здесь изображено, либо найти допущенные художником ошибки, либо прокомментировать какие-либо детали изображения.

Хорошим «учебным» примером может быть следующее задание:

(12) Определите, жизнь ююдей на каком этапе развития первобытного общества изобразил художник. Обоснуйme cboü ombem. 


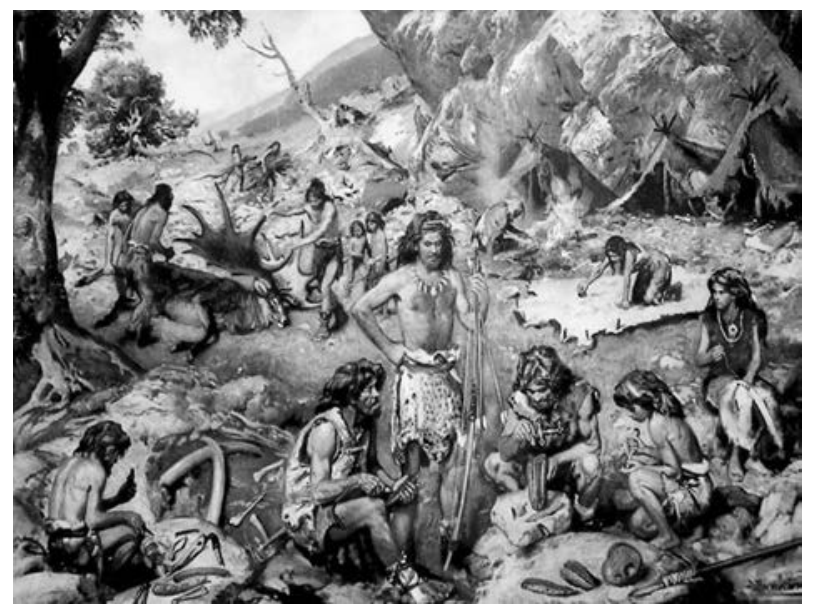

Ответ должен даваться в примерно следующем виде: на картине изображено общество эпохи мезолита - об этом свидетельствуют, с одной стороны, наличие у людей на переднем плане лука и микролитических орудий труда (все это появляется только в мезолите), а с другой стороны, отсутствие тканой одежды - все изображенные люди носят одежду из шкур животных (тканая одежда появится только в неолите).

Другой пример задания по картине:

(13) Какая неточность и почему допущена на картине В. М. Васнецьова «Бой скифов со славянами» (1881 г.)?

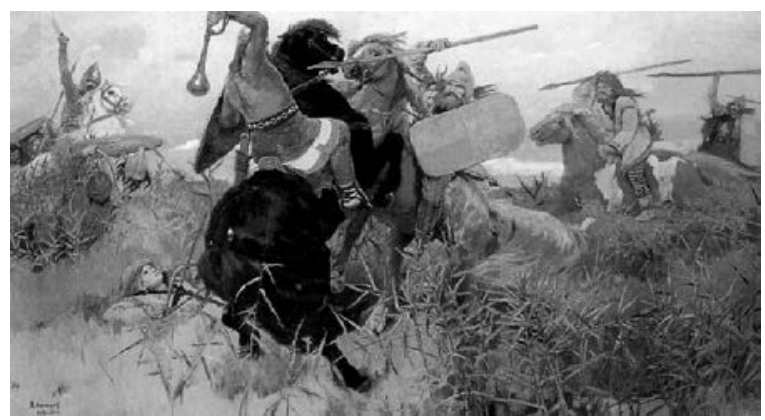




\section{7-й тип: вопросы по карте}

Интересной разновидностью работы со студентами «по картинкам» являются задания, связанные с объяснением карт. Задания такого рода позволяют связывать исторические и географические знания. Лучше всего, чтобы к изображению карты был не один вопрос, а серия тематически взаимосвязанных вопросов.

Вот хороший пример подобного задания:

(14) Какой период истории Рима отражен на карте? Как будут в дальнейшем изменяться его границы - расширяться или сужаться? Какими объективными факторами определялись завоевания Рима? Почему, например, он не стал завоевывать всю Афррику и Ближний Восток, ограничиваясь подчинением лишь территорий у побережья Средиземного моря?

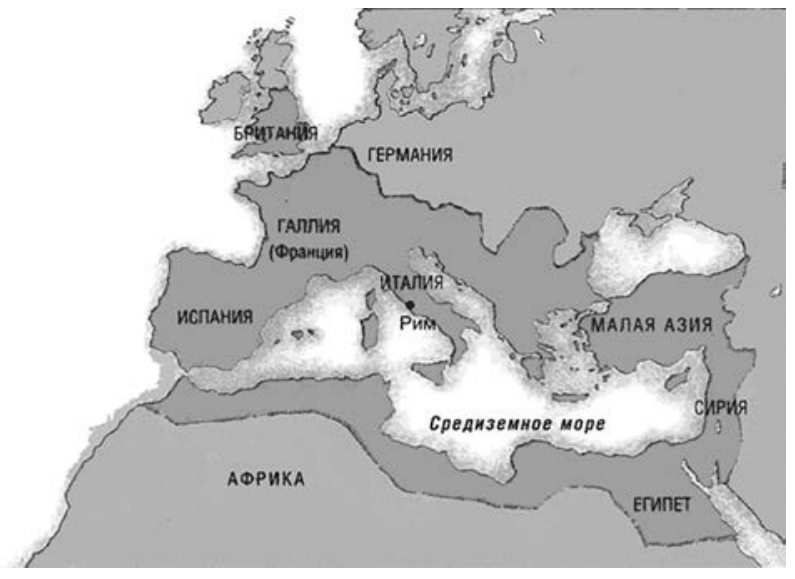

Для комплексного ответа на данный вопрос надо не просто помнить изображения из исторических атласов, но и хорошо представлять социально-экономические причины завоевательных войн в доиндустриальных обществах, а также знать социально-политическую ситуацию времен Римской империи на пограничных с нею территориях. 


\section{8-й тип: проанализируйте исторический первоисточник}

Этот тип задания требует от преподавателя хорошего знакомства с академическими или хотя бы с научно-популярными публикациями, в которых приводятся интересные (для учебного разбора) цитаты из исторических первоисточников.

В качестве примера можно привести такой вопрос:

(15) В алгебрачческом трактате персидского ученого ал-Хорезми (предположительно 783-850 гг.) «Краткая книга об исчислении алгебры» («Китаб аль-джебр Ва-ль-мукабала») есть раздел, посвященный практическому применению математических знаний. Вот некоторые задачи, которые разбираются в этой книге: «Работник, месячный заработок которого 10 дирхемов, работал 6 дней. Какова его доля?»; «Человек умер, оставив двух сыновей, и завешал треть своего имущества другому человеку. Он оставил 10 дирхемов наличными и отданное в долг, равное доле одного из сыновей. Сколько должен получить каждый из наследников?» (иит. no: [6]).

Какие выводы о соииально-экономических отношениях в Арабском халифрате начала IX b., где в основном жил и работал ал-Хорезми, можно сделать на основании этих задач? Какой научный термин, активно используемый современными математиками и экономистами, связан с именем ал-Хорезми и почему?

А вот другой удачный пример подобного задания:

(16) В XVI в. испанский монах Игнатий Лойола основал новый монашеский орден, о котором писал императору Священной Римской империи Карлу V следующее: "Для борьбы со злом, распространившемся и свирепствующем В Германии, следует прежде всего отдать предпочтение такому средству, как университеты, которые, служа примером религиозной жизни и иелостности католического учения, приводят учащихся к добру. Использование этого 
средства представляется не только благоразумным, но и необходимым, и внушенным Богом».

О каком ордене идет речь? С чем связано появление этого ордена? Удалось ли этому ордену стимулировать развитие университетов? Какие известные ученые и просветители принадлежали к этому ордену или обучались в его школах?

\section{9-й тип: объясните, что имел ввиду писатель}

Этот тип заданий является по существу разновидностью предыдущего, только здесь в качестве исходного исторического источника выступает не исторический документ, а литературные произведения давних времен (включая, например, Библию). Он рассчитан в первую очередь на всесторонне развитых студентов с широким гуманитарным кругозором, поскольку чтобы качественно ответить на такие вопросы, необходимо хорошо знать не только историю, но и классическую литературу.

Вот пример подобного задания.

(17) В знаменитой комедии А. С. Грибоедова «Горе от ума» приводится диалог Фамусова и Хлестовой, обсуждающзих, сколько крепостных имеет Чаикий:

«Хиестова

А Чацкого мне жаль.

По-христиански так; он жалости достоин;

Был острый человек, имел душ сотни три.

Фамусов

Yemыре.

Хлестова

Hет! Триста! - уж чужих имений мне не знать!».

Какую информацию о Чаиком хотел 8 этом эпизоде сообиить писатель?

а) Чацукий - мелкий помещуик, его недовольство окружающим связано и с плохим мичным материальным положением; 
б) критикуя крепостничество, Чаикий сам имеет много крепостных, поэтому он проявляет непоследовательность своих взглядов;

в) Чацзкий - дворянин обычного для тех лет достатка;

2) главным мерилом богатства дворян $b$ эпоху крепостного права были не деньги, а крепостные;

д) Чаикий - богатый помещик, поэтому он может не служить и «фрондировать», не боясь лишиться средсть к жизни.

В данном примере наиболее правильным ответом будет д). В то же время в принципе допустим и ответ г), но для современников, слушателей комедии А. С. Грибоедова, это было общеизвестным фактом, не требующим напоминания. Вариант б) тоже в определенной степени справедлив, однако это будет интерпретацией ситуации с современной точки зрения: в эпоху крепостного права дворяне либеральных взглядов (например, декабристы) практически никогда не давали вольную своим крепостным, поскольку не хотели остаться без одного из главных источников своих доходов.

При составлении задач такого типа можно использовать эпизоды из Библии - например, про денарий кесаря (Матф., 22:15-22) или про работников в винограднике (Матф., 20:9-14). Из русской классической литературы для таких заданий хорошо подходят, например, произведения Н. В. Гоголя («Мертвые души» и «Ревизор» как источники по теневой экономике николаевской России).

\section{0-й тип: прокомментируйте загадку истории}

Это - наиболее креативный тип учебных заданий. История отличается от других научных дисциплин тем, что ее нерешенные проблемы (кем были Рюрик и варяги? был ли Дмитрий самозванцем? получал ли Ленин от Германии деньги на революцию? какова роль ленд-лиза в Великой Отечественной войне? и др.) 2017. T. 18, № 3. C. 547-570 
активно освещаются в популярной литературе очень разного уровня научности и добросовестности. Преподаватель просто обязан в ходе учебного процесса подчеркивать, что многие вопросы пока не имеют однозначных и общепринятых ответов. Студенты должны в таких случаях получить представление об основных подходах к ответам на «загадки истории» и знать аргументы «за» и «против» этих подходов. В то же время от настоящих «загадок истории» надо отличать мнимые «загадки» (например, концепции «новой хронологии» Фоменко и его последователей), которые хотя и имеют хождение в популярной литературе, но находятся за рамками науки, поскольку формулировка этих «загадок» связана с «передергиванием» хорошо установленных исторических фактов, с логическими ошибками и т. д. Во многих случаях «загадочность» возникает не изза целенаправленного стремления автора сообщения доказать какую-либо сомнительную идею, не брезгуя искажением фактов, а случайно - например, из-за неточной передачи фактов.

Приведем пример учебного задания по одной из реальных исторических загадок:

(18) В Павлиньем зале Эрмитажа на полу выложена копия оригинальной римской мозаики, обнаруженной около Рима в 1780 г. при раскопках терм древнеримского города Окрикулума. Фрагмент мозаики, который изображает размичные продукты, вызывает дискуссию.

вот это - более общий вид мозаики.

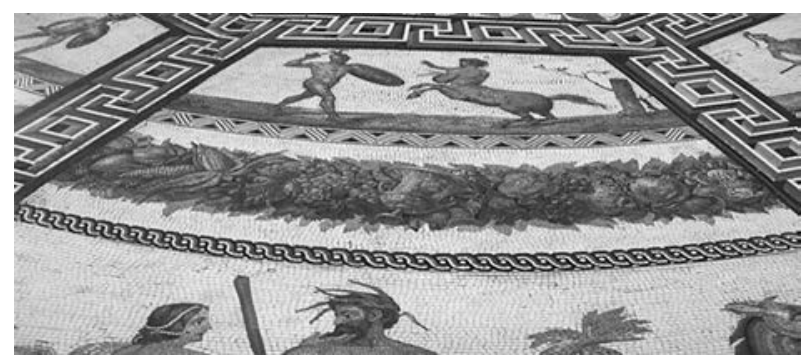

2017, vol. 18 , no. 3 , pp. 547-570 
А это - тот самый фрагмент мозаики, по поводу которого идут дискуссии.

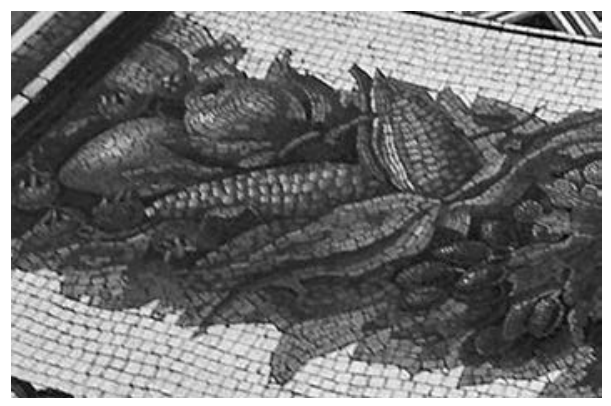

Некоторые рассматривают его как доказательство очень ранних контактов между Старым и Новым Светом. Другие утверждают, что эта мозаика опровергает древний характер античного мира.

Объясните, в чем причина дискуссий, что вызывает недоумение. Какие есть объяснения этой загадки?

\section{1-й тип: расчетные задания}

Это - наиболее важный тип задач в системе современного экономического образования. Разбор таких заданий должен приучать студентов-первокурсников к использованию методов экономико-математического моделирования.

К сожалению, их составлять и применять довольно сложно. С одной стороны, по истории доиндустриальных эпох просто не так уж много количественных баз данных (имеющиеся - в основном по исторической демографии и исторической статистике доходов [3; 5]). С другой стороны, преподаванием экономической истории в современных отечественных вузах занимаются в основном преподаватели-историки, для которых академическая наука ассоциируется скорее с работой над архивными документами, чем с клиометрическими разработками. 
Тем не менее, такие задания тоже реально используются в преподавании. Для их составления надо использовать в первую очередь существующие клиометрические работы [1].

Приводим оригинальный пример этого редкого типа учебных заданий

(19) К числу исторических загадок относится история о «кладе гетмана Полуботка». Согласно преданию, в начале XVIII b. этот украинский политик будто бы передал на хранение в крупный английский банк (Банк Ост-Индской компании или Банк Ллойда) крупную сумму денег - две бочки золотых монет (называют сумму в 500 тыс. червониев) под 2,5 \% (или даже 7,5 \%) годовых. Поскольку гетман был в 1723 г. репрессирован Петром I и умер в заключении, то вклад остался не востребованным. Многократно предпринимались попытки вернуть этот вклад (последний раз уже в 1990-е гг. Властями Украины), однако банки Великобритания отказываются признавать вклад Полуботка.

Ответьте на следуюшие вопросы.

1) Предположим, что гипотетический вклад на самом деле был сделан в 1723 г. под 2,5 \% годовых и составлял 500 тыс. золотых червониев времен Петра I. Рассчитайте в весовом золоте и $b$ современной валюте, какой величины должен достигнуть этот вклад через 300 лет (к 2023 г.). Cопоставьте это с величинои современного золотого запаса Великобритании или России.

2) Предположим теперь, что у наследников, которые требуют возвращения вклада, сделанного 300 лет назад, будет документальное подтверждение. Представляют ии такие супердолгосрочные вклады опасность для банков? Предпринимали ли банки против них какие-либо специиальные меры предосторожности?

3) Какие характеристики истории финансовой системы препятствуют обогащению предков за счет вкладов, сделанных их далекими предками? 
Хотя собственно математическая часть данного задания может быть выполнена за несколько минут, однако развернутый ответ на задачу требует от студентов поиска дополнительной информации (например, о весе российских червонцев начала XVIII в.), поэтому данная задача должна задаваться только на дом, для самостоятельной исследовательской работы студентов. Можно дополнительно усложнить эту задачу - предложить студентам прочитать рассказ американского фантаста М. Рейнольдса «Наросло по процентам», где история о супердолгосрочном вкладе изложена в гиперболизированной форме, и оценить ее правдоподобность.

\section{2-й тип: комплексные задания}

Речь идет о задании, которое состоит из «цепочки» взаимосвязанных вопросов по какой-либо проблеме. В предыдущем изложении по существу уже приводились примеры таких заданий - это задачи (14), (15), (16) и (19). С точки зрения преподавателя, достоинство данного задания в том, что, отвечая на подобный вопрос, студент должен по существу написать (или устно изложить) своего рода мини-эссе. На семинаре анализ таких вопросов целесообразно проводить в форме группового обсуждения.

Примером такого вопроса может быть следующее задание:

(20) Расскажите о социально-экономических аспектах Крестовых походов.

1) Почему походы европейцев за освобождение «сьятых мест» начались только в коние XI b., хотя мусульмане завоевали Палестину еще в начале VII b.? Подсказка: свяжите ответ на этот вопрос с социально-экономическим развитием Западной Европы в раннее средневековье - b частности, с «папской революиией» и с развитием средиземноморской торговли. 
2) У Ф. Энгельса есть следующее высказывание: «Разве феодализм когда-либо соответствовал своему понятию? ... Он более всего приблизился к своему понятию в эфемерном Иерусалимском королевстве, которое оставило после себя $b$ "Иерусалимских ассизах" наиболее классическое выражение фреодального порядка» [7, с. 356]. Что он имел ввиду? Почему в Иерусалимском королевстве "феодальный порядок» оказался более классическим, чем в самой Западной Европе?

3) В силу каких экономических причин участники Четвертого крестового похода вместо освобождения Палестины стали завоевателями Константинополя? Почему участники похода были вынуждены под давлением венецианцев штурмовать византииские города, хотя некоторые из крестоносиев сиитали это отступлением от долга?

4) Каковы позитивные и негативные последствия Креcmobых походов для Западной Европы и для народов Ближнего Востока?

\section{3-й тип: прокомментируйте казус}

Речь идет о разборе какого-то исторического «анекдота» - интересного и малоизвестного факта, в котором в концентрированном виде проявляются важные закономерности развития общества.

Вот пример такого задания:

(21) Классическим и общеизвестным примером приключенческой литературы является роман Жюля Верна «Вокруг света за 80 дней» (1872 г.). Менее известно, что вскоре после выхода этого романа были сделаны успешные попытки реально осуществить быстрое кругосветное путешествие: американская журналистка Нелии Блай $b$ 1889 г. описала свои приключения В книге «В 72 дня вокруг света», а В 1891 г. улучшила рекорд, совершив «кругосветку» уже только за 66 дней. В 1928 г. датчанин Палие Хулд в честь столетия со дня рождения Жюля Верна объехал Земюю всего за 44 дня. Однако после 1940-х гг. попытки повторить путешествие Филеаса Фогга - быстро объехать мир 
при помощи железных дорог, машин и морских кораблей прекратились. Хотя с 1990-х г2. появился переходящий «Приз Жюля Верна» («Jules Verne Trophy»), он вручается за самое быстрое кругосветное путешествие, совершенное не по суше, а по морю (на яхте).

Что изменилось в 1940-е гг. и резко замедлило возможность переезжать из страны в страну? Подсказка: с какими трудностями сталкиваются обычные современные туристы, желающие просто провести отпуск в другой стране? Как развиваются возможности снизить эти издержки?

А вот еще более креативный пример «казусного» задания:

(22) XVII век называют «золотым» веком голандской школы живописи. Художники писали десятки и сотни картин: например, Якоб ван Рейсдал написал 1075 картин, Адриан ван Остаде - 920, Ян Стен и Альберт Кёйп - около 900. При этом художники за редким исключением (например, таких гениев как Рембрандт или Хальс) специиализировалось на определенном жанре живописи: натюрморте, пейзаже, бытовых сиенах, портрете. Более того, внутри жанров довольно часто тоже существовала специиализация, например, в жанре пейзажа одни художники писали марины (морские пейзажи), другие - ведуты (Виды городов), третьи - зимние пейзажи и т. д. Какие выводы о состоянии голандской экономики в XVII b. можно сделать на основании приведенных ниже фактов?

Ответ на данный непростой вопрос, требующий умения соединять анализ тенденций развития экономики и культуры, может быть дан в приблизительно следующей форме: «Приведенные факты свидетельствуют об огромном спросе на картины. Это, во-первых, является показателем высокого уровня жизни населения, а следовательно, богатства страны и высокого уровня развития ее экономики. Во-вторых, это показатель окончательного утверждения рыночных отноше2017. T. 18, № 3. C. 547-570 
ний в экономике Голландии XVII в. - сформировался не только рынок обычных потребительских товаров, но уже и художественный рынок, на котором спрос рождает предложение, и художники пишут картины не для конкретного заказчика, как это было раньше, а для продажи любым потребителям стандартной продукции».

Сотрудниками департамента экономической теории Финансового университета в настоящее время под руководством научного руководителя департамента Д.э.н. профессора Р. М. Нуреева готовится «Практикум по экономической истории», где будут задачи всех перечисленных видов. Разработчики будут рады, если преподаватели экономической истории других вузов России подскажут, задания каких еще типов желательно включать в готовящийся «Практикум».

\section{Өписок использованной литературы}

1. Латов Ю. В. Клио берет калькулятор (клиометрические case-study по институциональной экономической истории российской цивилизации) / Ю. В. Латов / / Journal of Institutional Studies. - 2012. - № 2. С. 50-73.

2. Ленин В. И. Аграрная программа социал-демократии в русской революции. Автореферат / В. И. Ленин // Полн. собр. соч. 5-е изд. - М. : Политиздат, 1968. - Т. 17. - С. 148-173.

3. Ливи Баччи М. Демографическая история Европы / М. Ливи Баччи. - СПб. : Alexandria, 2010. - 298, [2] c.;

4. Материалы по экономической истории Китая в ранее средневековье: (Разд. «Ши Хо Чжи» из династийн. историй) / пер. с кит. - М. : Наука, 1980. $256 \mathrm{c.}$

5. Мэддисон Э. Контуры мировой экономики в 1-2030 гг. : очерки по макроэкономической истории / 
Э. Мэддисон; пер. с англ. - М. : Изд-во Института Гайдара, 2012. - 581, [1] с.

6. Сираджинов С. Х. Ал-Хорезми - выдающийся математик и астроном средневековья: пособ. для учащихся. - М. : Просвещение, 1983. - 79 с.

7. Энгельс Ф. Письмо Конраду Шмидту, 12 марта 1895 г. / Ф. Энгельс // Маркс К., Энгельс Ф. Соч., 2-е изд. - М.: Политиздат, 1966. - Т. 39. - С. 353-358.

\section{Информация об авторах}

Латов Юрий Валерьевич - доктор социологических наук, кандидат экономических наук, ведущий научный сотрудник, Институт социологии РАН; профессор, департамент экономической теории, Финансовый университет при Правительстве РФ, Российская Федерация, 125993, г. Москва, Ленинградский проспект, д.49, e-mail: latov@mail.ru

Воскресенская Нина Олеговна - кандидат исторических наук, доцент, департамент экономической теории, Финансовый университет при Правительстве РФ, Российская Федерация, 125993, г. Москва, Ленинградский проспект, д.49, e-mail: ninaolvoskr@ gmail.com

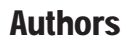

Yury V. Latov - D.Sc. in Sociology, Ph.D. in Economics, Leading Researcher, Institute of Sociology RAS; Professor, Department of Economic Theory, Financial University under the Government of the Russian Federation, 49, Leningradsky Prospekt, Moscow, 125993, Russian Federation, e-mail: latov@mail.ru

Nina O. Voskresenskaya - Ph.D. in History, Associate Professor, Department of Economic Theory, Financial University under the Government of the Russian Federation, 49, Leningradsky Prospekt, Moscow, 125993, Russian Federation, e-mail: ninaolvoskr@gmail.com 


\title{
Для цитирования
}

\begin{abstract}
Латов Ю. В. «Чёртова дюжина» помощников преподавателю: основные типы творческих учебных заданий при преподавании экономической истории / Ю. В. Латов, Н. О. Воскресенская / / Историко-экономические исследования. - 2017. - Т. 18, № 3. - С. 547-570. DOI: 10.17150/2308-2588.2017.18(3).547-570.
\end{abstract}

\section{$47: 4 \sin ^{3}$}

Latov Yu. V., Voskresenskaya N. O. «Baker's Dozen» of Teacher's Helpers: Basic Types of Creative Learning Activities of Economic History Teaching. Istorikoekonomicheskie issledovaniya = Journal of Economic History $\mathcal{E}$ History of Economics, 2017, vol. 18, no. 3, pp. 547-570. DOI: 10.17150/2308-2588.2017.18(3).547-570. (In Russian). 